\title{
Nonlinear finite element analysis of three implant- abutment interface designs
}

\author{
Chun-Bo Tang ${ }^{1, *}$, Si-Yu Liu ${ }^{1, *}$, Guo-Xing Zhou ${ }^{1}$, Jin-Hua Yu ${ }^{1}$, Guang-Dong Zhang ${ }^{1}$, Yi-Dong Bao ${ }^{2}$ \\ and Qiu-Ju Wang ${ }^{2}$
}

The objective of this study was to investigate the mechanical characteristics of implant-abutment interface design in a dental implant system, using nonlinear finite element analysis (FEA) method. This finite element simulation study was applied on three commonly used commercial dental implant systems: model I, the reduced-diameter $3 \mathrm{i}$ implant system (West Palm Beach, FL, USA) with a hex and a 12-point double internal hexagonal connection; model II, the Semados implant system (Bego, Bremen, Germany) with combination of a conical ( $45^{\circ}$ taper) and internal hexagonal connection; and model III, the Brånemark implant system (Nobel Biocare, Gothenburg, Sweden) with external hexagonal connection. In simulation, a force of $170 \mathrm{~N}$ with $45^{\circ}$ oblique to the longitudinal axis of the implant was loaded to the top surface of the abutment. It has been found from the strength and stiffness analysis that the $3 \mathrm{i}$ implant system has the lowest maximum von Mises stress, principal stress and displacement while the Brånemark implant system has the highest. It was concluded from our preliminary study using nonlinear FEA that the reduced-diameter $3 \mathrm{i}$ implant system with a hex and a 12-point double internal hexagonal connection had a better stress distribution, and produced a smaller displacement than the other two implant systems.

International Journal of Oral Science (2012) 4, 101-108; doi:10.1038/ijos.2012.35; published online 15 June 2012

Keywords: external hexagonal connection; finite element analysis; implant-abutment interface; internal hexagonal connection; nonlinear analysis

\section{INTRODUCTION}

Nowadays, titanium endosteal implants therapy has been widely used in clinical application for partially or completely edentulous patient. ${ }^{1-3}$ This is due to the superior mechanical properties and excellent anchorage in the jawbones. ${ }^{4}$ With the increasing demand and clinical applications of dental implants, more and more implant-abutment interface related designs and performance issues have been investigated and reported. ${ }^{5-6}$ Micromovements and vibrations due to occlusal forces can lead to mechanical complications, such as loosening of screws and fracture of the abutment or implant. The reliability and stability of the implant-abutment connection design is a crucial factor in maintaining a long-term functioning of the implant-bone interface. ${ }^{7}$

Currently, there are over 20 different geometric variations of implant-abutment interface commercially available. Implant-abutment connection can be either internal or external, depending on if a geometric feature extends above the coronal surface or below. External connection was first used clinically and had dominated the market for the past two decades until recently a number of internal connection designs have become popular and rapidly taken over the world market. ${ }^{8}$ It has been previously reported that although axial load produces similar level of stress on the interface regardless of design, the internal-hex interface design yields a lower stress concentration than the external-hex interface design under an off-center load. ${ }^{9-10}$ More recently, a new design of abutment-implant connection, namely platform switching, is attracting more attention. Rodriguez-Ciurana et al. ${ }^{11}$ show that an implant system with abutment diameter smaller than that of the implant platform can achieve better results than an implant system with implant platform and abutment of the same diameter, even though their initial biomechanical load potential was lower.

With the continuous improvement of implant-abutment interface design, the structural complicity has made it difficult to calculate occlusal forces in the bone around dental implant and the stress within implant. In order to predict stress and strain within structures in a real situation, which cannot be solved by a traditional linear static model, nonlinear finite element analysis (FEA) has become an increasingly powerful approach. ${ }^{12}$ Nonlinear FEA has been successfully applied to assess the mechanical characteristics of the implant-abutment connection in loading tooth- and implant-supported prostheses. ${ }^{13-14}$ However, most of the previous reports are lack of rigorousness in model construction, for example the simple computer-aided design (CAD) geometry modeling, ${ }^{9}$ less FEM model meshes and small number of elements and nodes in the finite element model. ${ }^{13}$

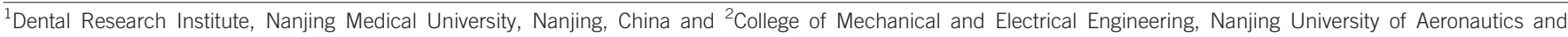
Astronautics, Nanjing, China

*These authors contributed equally to this work.

Correspondence: Dr CB Tang, Institute of Stomatology, Nanjing Medical University, 136 Hanzhong Road, Nanjing 210029, China

E-mail: cbtang@njmu.edu.cn

Received 9 February 2012; accepted 26 April 2012 
In this study, we selected three commercially available implant systems for strength and stiffness analysis by ABAQUS software to compare the differences and similarities, and to determine the most advantageous implant system among the three. Our study provides in-depth information for clinical dentists to understand the implant structure and how different design affects the performance of the implant system in clinics. Further, nonlinear FEA can also be applied, in a retrospective manner, to optimize the design for a better implant restoration process.

\section{MATERIALS AND METHODS}

\section{CAD geometry modeling}

Through three-dimensional optical scanning and point cloud data extraction, three CAD models were built using reverse engineering technique. Model I was the reduced-diameter $3 \mathrm{i}$ implant system $(\varnothing$ $4.0 \mathrm{~mm} \times 13 \mathrm{~mm}$; West Palm Beach, FL, USA) having a hex and a 12point double internal hexagonal abutment $(\varnothing 3.75 \mathrm{~mm} \times 6 \mathrm{~mm})$ with a connection depth of $4 \mathrm{~mm}$ (Figure 1a). Model II was the Semados implant system (Ø $4.0 \mathrm{~mm} \times 13 \mathrm{~mm}$; Bego, Bremen, Germany) fea-

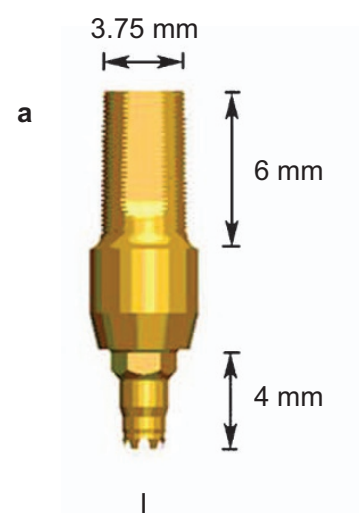

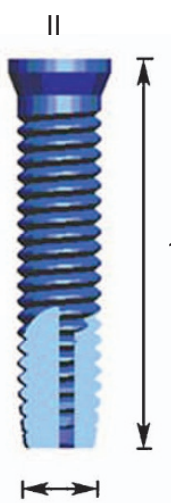

$4 \mathrm{~mm}$

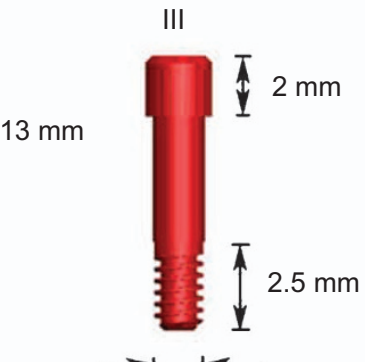

$1.2 \mathrm{~mm}$

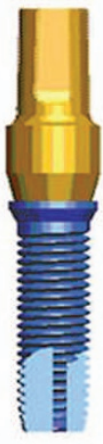

IV

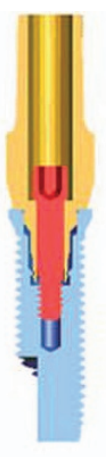

V
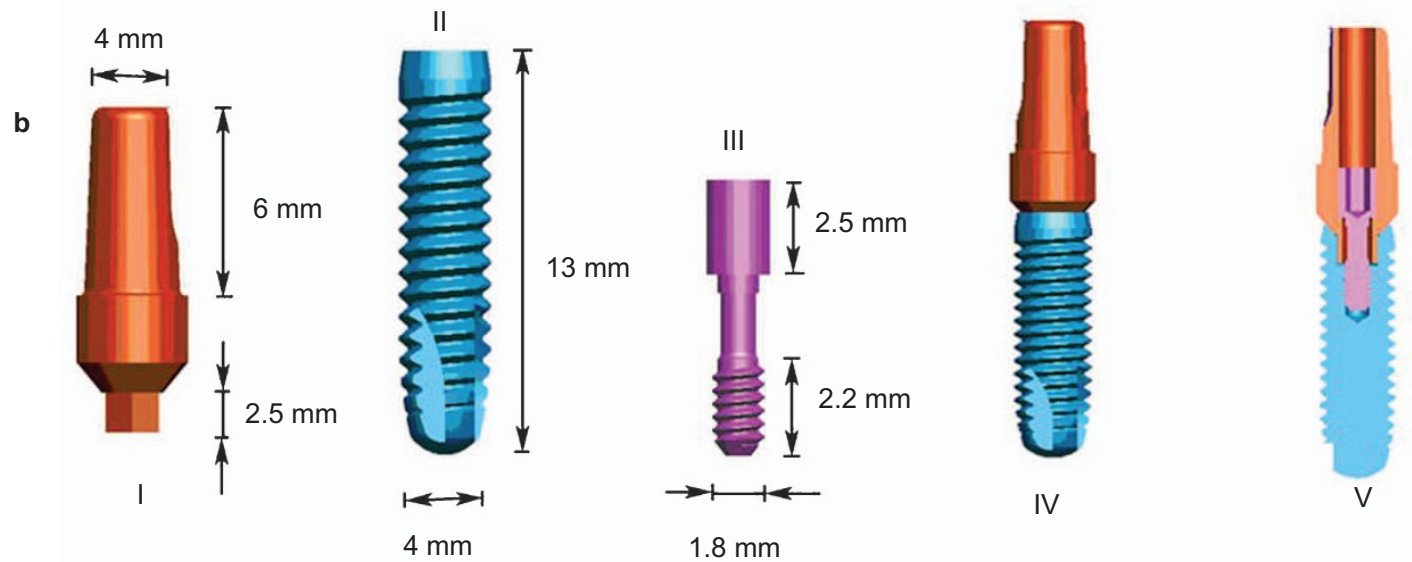

$1.8 \mathrm{~mm}$

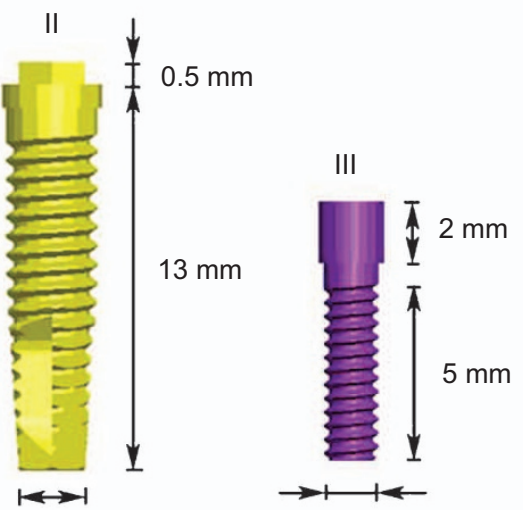

$1.5 \mathrm{~mm}$

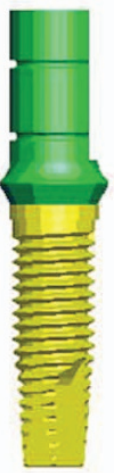

IV

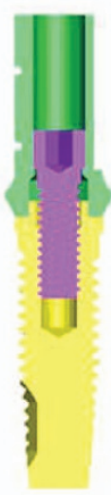

V

Figure 1 CAD geometry model and size of three implant systems. (a) 3i implant system, (b) Semados implant system and (c) Brånemark implant system. (I) Abutment, (II) Implant, (III) Screw, (IV) Assembled implant system and (V) Section view of implant system. CAD, computer-aided design. 

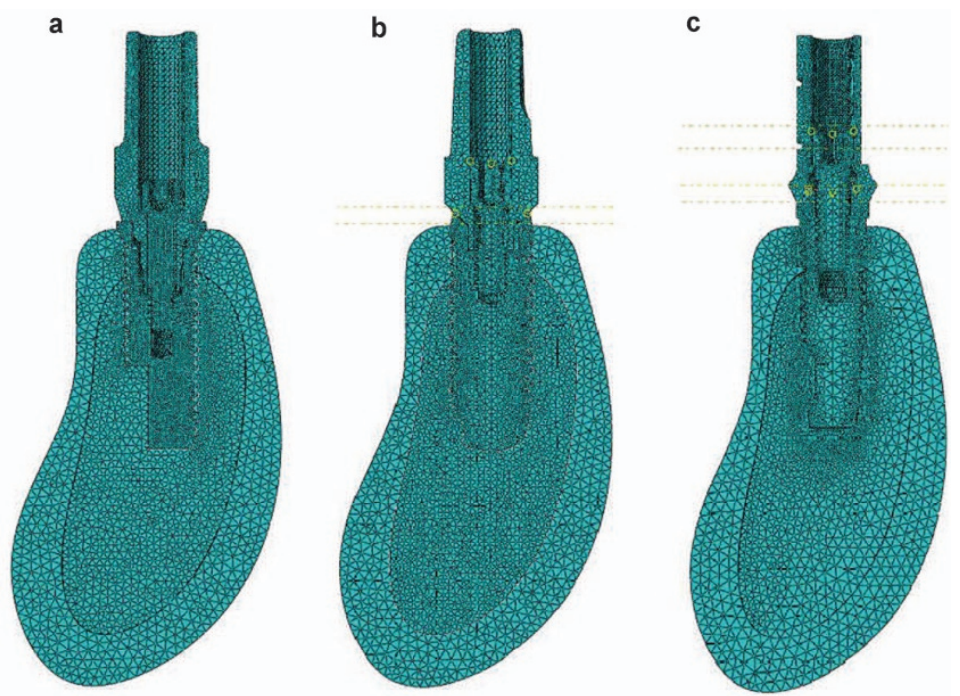

Figure 2 Finite element models of three implant systems. All components of finite element models were meshed with tetrahedron element. (a) Model I contains 44450 nodes and 208438 elements, (b) model II contains 49005 nodes and 242972 elements and (c) model III contains 49558 nodes and 244047 elements.

Table 1 Node and element numbers for all components of the models

\begin{tabular}{|c|c|c|c|c|c|c|c|}
\hline Category & Model & Abutment & Implant & Screw & Cortical bone & Cancellous bone & Sum \\
\hline \multirow[t]{3}{*}{ Nodes } & $3 i$ & 6256 & 10989 & 1875 & 8311 & 17019 & 44450 \\
\hline & Semados & 2485 & 8475 & 3440 & 8147 & 26458 & 49005 \\
\hline & Brånemark & 3727 & 6462 & 2224 & 7532 & 29613 & 49558 \\
\hline & Semados & 10497 & 38851 & 14113 & 37390 & 142121 & 242972 \\
\hline & Brånemark & 16153 & 28236 & 8473 & 34085 & 157100 & 244047 \\
\hline
\end{tabular}

turing a conical $\left(45^{\circ}\right.$ taper $)$ internal hexagonal abutment $(\varnothing$ $4.0 \mathrm{~mm} \times 6 \mathrm{~mm}$ ) with a connection depth of $2.5 \mathrm{~mm}$ (Figure $1 \mathrm{~b}$ ). Model III was the Brånemark implant system ( $\varnothing 4.0 \mathrm{~mm} \times 13 \mathrm{~mm}$; Nobel Biocare, Gothenburg, Sweden) with an external hexagonal abutment $(\varnothing 4.0 \mathrm{~mm} \times 6 \mathrm{~mm})$ and a connection depth of $0.5 \mathrm{~mm}$ (Figure 1c). A bone block model was also constructed based on a cross-sectional image of the human mandible in the molar region, $25 \mathrm{~mm}$ high, $12 \mathrm{~mm}$ wide and $10 \mathrm{~mm}$ thick, consisting of a spongy center surrounded by a 2-mm cortical bone. The implant was positioned in the cortical and cancellous bone block. Such configuration allows refined simulation of all models in Pro/Engineer Wildfire 3.0 (PTC, Needham, MA, USA).

\section{Three-dimensional FEM modeling}

We imported the three-dimensional CAD geometry models into ABAQUS 6.6 to generate finite elements and perform the numerical simulation. Symmetrical geometry of the implant allows us to perform simulation on only half of the model to expedite this process. All components were meshed with tetrahedron element (Figure 2 and Table 1) by using C3D4 type elements readily available in ABAQUS element library.

\section{Boundary conditions and constraints}

In this study, we assumed the implant, abutment and screws were homogeneous, linear elastic, and isotropic mechanical properties. But cortical and cancellous bones were treated as anisotropic. Material properties for bone and implant components (as summarized in Table 2) were collected from reliable resources and published data. ${ }^{15-16}$ The implant was pure titanium and other components were titanium alloys, with homogeneous and isotropic elastic properties. Further, complete osseointegration between the implant and the surrounding bone was assumed, and the models were constrained in $\mathrm{X}$-, $\mathrm{Y}$ - and Z-directions on implant surface. The model's symmetric property allowed us to focus on half of the model for analysis, i.e. the symmetry constraints on the Z-, RX-, RY- directions. Nonlinear contact zones were defined at four critical interfaces: implant-bone, implant-abutment, implant-screw and abutment-screw. Contact analysis defined the load and deformation transfer between different components. The friction coefficient $(\mu)$ was set as 0.3 between all the titanium-titanium interfaces, ${ }^{17} 0.65$ for the cortical bone-implant interface; $^{18}$ and 0.77 for the cancellous bone-implant interface. ${ }^{19}$ Per manufacturer's recommendation, we initially applied a clockwise horizontal rotational torque load of $35 \mathrm{~N} \cdot \mathrm{cm}$ on the abutment screw during the installation stage.

\section{Loading conditions}

A distributed force of $170 \mathrm{~N}$ was applied onto the top surface of the abutment obliquely at $45^{\circ}$ to the longitudinal axis of the implant (Figure $3 a) .{ }^{20}$ Due to the structural symmetry, the load applied on

Table 2 Materials properties adopted in the study

\begin{tabular}{lccc}
\hline Material & Young's modulus/GPa & Poisson's ratio & References \\
\hline Cortical bone & 13.4 & 0.30 & 15 \\
Cancellous bone & 1.37 & 0.30 & 15 \\
Titanium alloys & 110 & 0.33 & 16 \\
Pure titanium & 110 & 0.33 & 16 \\
\hline
\end{tabular}


a

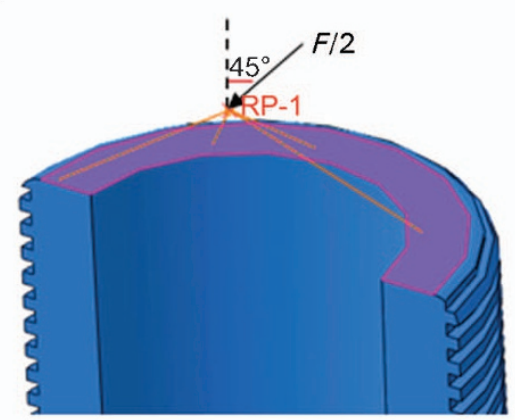

b

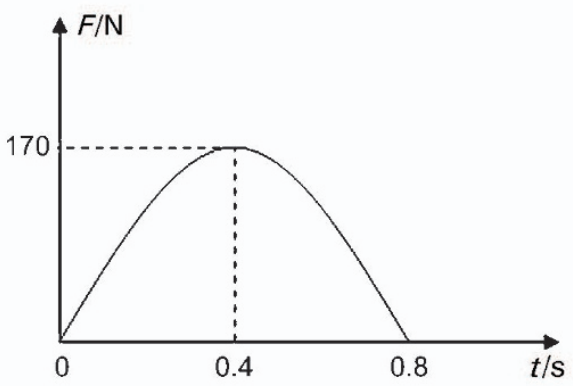

Figure 3 Loading direction and mode. (a) A force of $170 \mathrm{~N}$ was applied onto the top surface of the abutment obliquely at $45^{\circ}$ to the longitudinal axis of the implant. Due to the structural symmetry, the load applied on the model was $F / 2$. (b) The loading period was $0.8 \mathrm{~s}$, and its amplitude followed semi-sinusoidal pattern. The force values varied from 0 to $F / 2$ with time, however the loaded angle was constant.

the model was $F / 2$. The loading period was $0.8 \mathrm{~s}$, and its amplitude varied from 0 to $F / 2$ following a semi-sinusoidal pattern (Figure $3 b$ ). During simulation, a reference point was first created and the calculation of top surface was performed in accordance with a coupling constraint between this reference point and the top surface.

FEA

In this study, we selected three currently popular implant models to investigate the stress distribution in the implant-abutment connection systems. For a direct and systematic comparison, the same load conditions, boundary conditions and constraints were applied in all three models. ABAQUS/Standard solver (installed to a desktop computer with a Pentium 4 processor and 2 GB memory, and ran under Windows XP operating system) was used to analyze model data and perform the stress analysis in the implant system subject to an oblique periodical loading.

\section{RESULTS}

\section{Strength analysis}

The data obtained from ABAQUS calculation can be presented in a stress distribution map with a color scale, which makes it possible to directly compare the stress level in various component structures of all models. All stress values are shown in Figure 4. It can be seen from Figure 4 that a connection with a hex and a 12-point double internal hexagonal connection generates the minimum stress, while the external hexagonal connection has the highest. The stress distribution in model I is found to be concentrated in the abutment neck and the connection section where the abutment inserts deep into the implant, while the stress concentration regions in model II and model

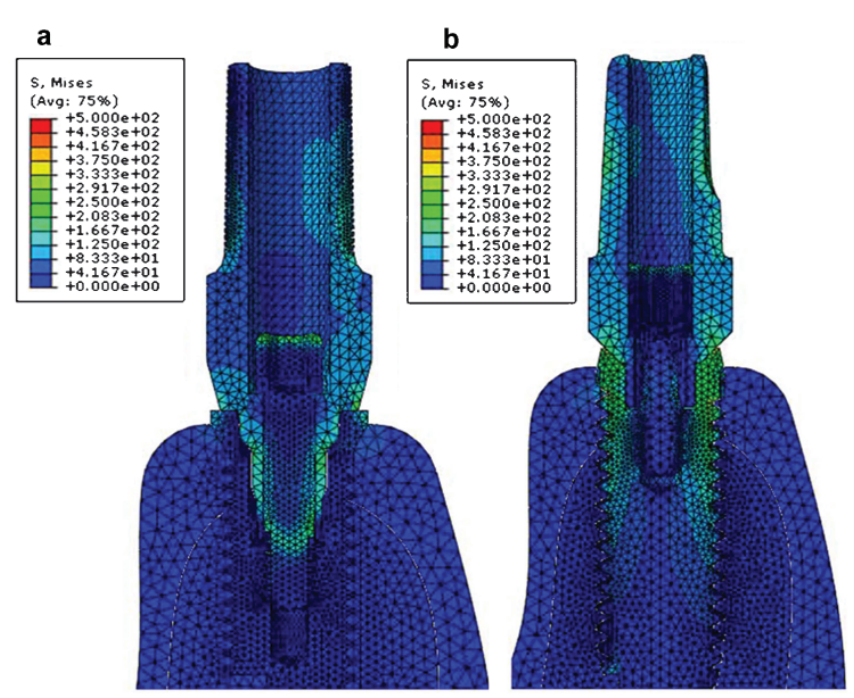

C

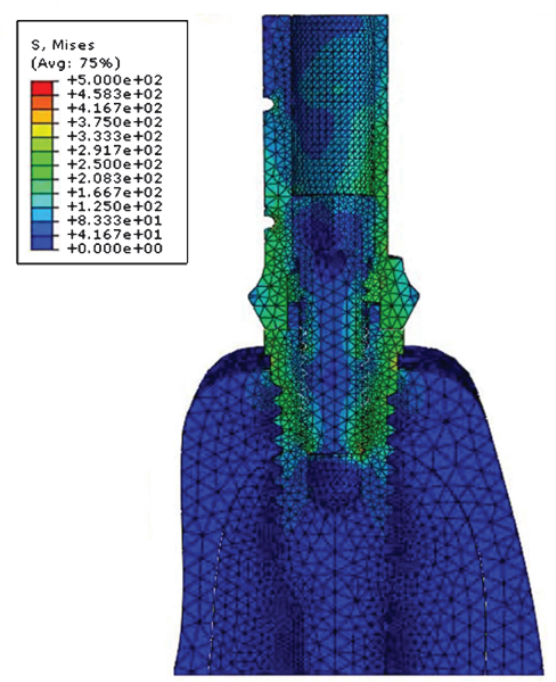

d

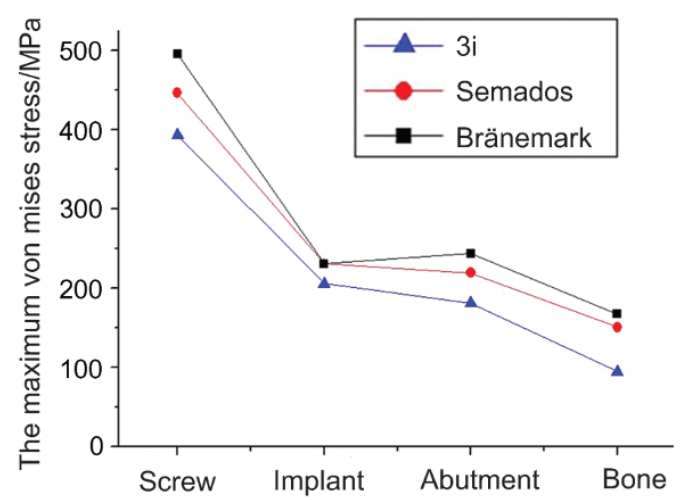

Figure 4 Stress distribution and maximum von Mises stress in three models. The stress of distribution is in (a) model I, (b) model II and (c) model III under the same loading condition, respectively. (d) The maximum von Mises stress values in all components of three models.

III are locating at the lower one-third of the abutment and first, second and third thread of the implant. In addition, the calculated von Mises stress is quite different with the three models. For all models, the highest von Mises stress occurs on the abutment screw. Screw in 
a

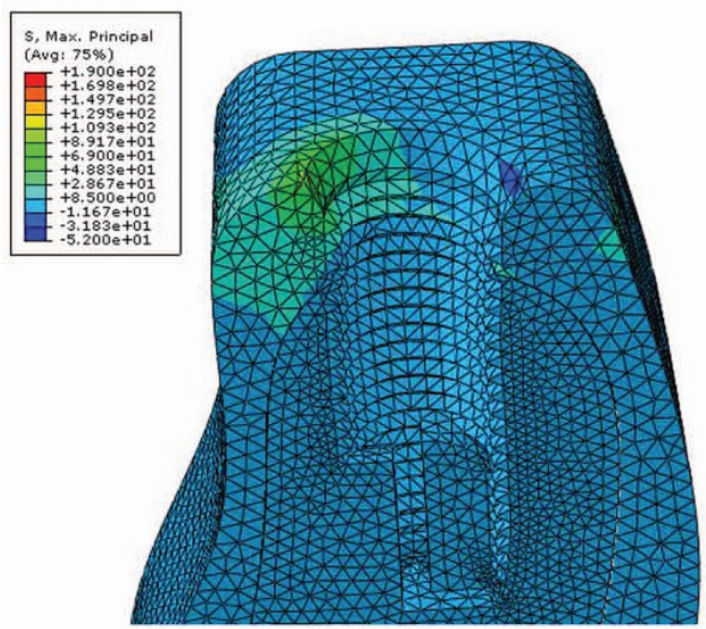

C

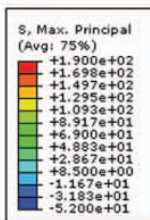

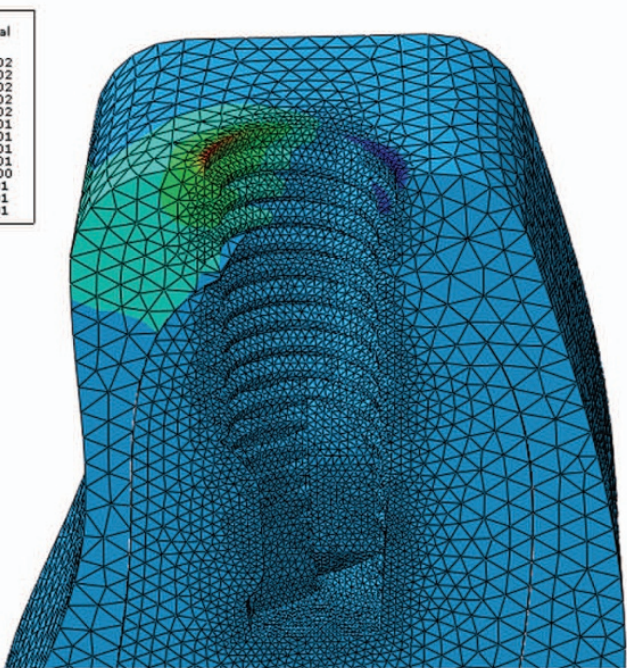

b

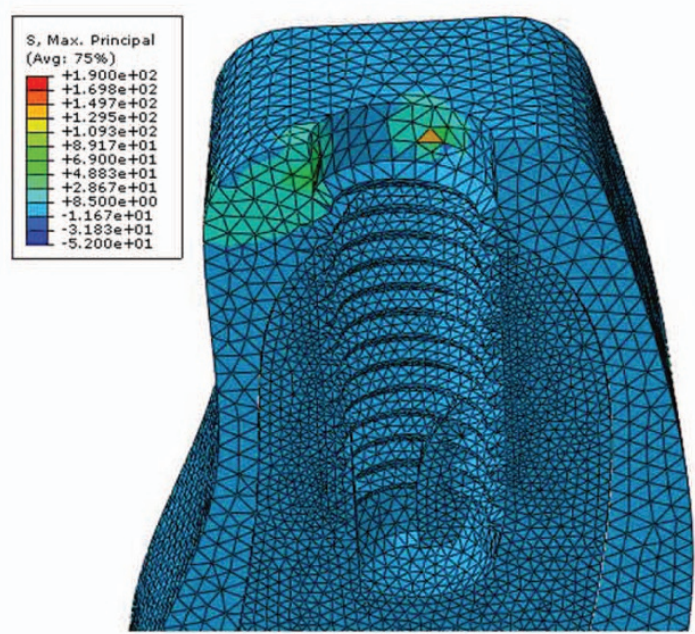

d

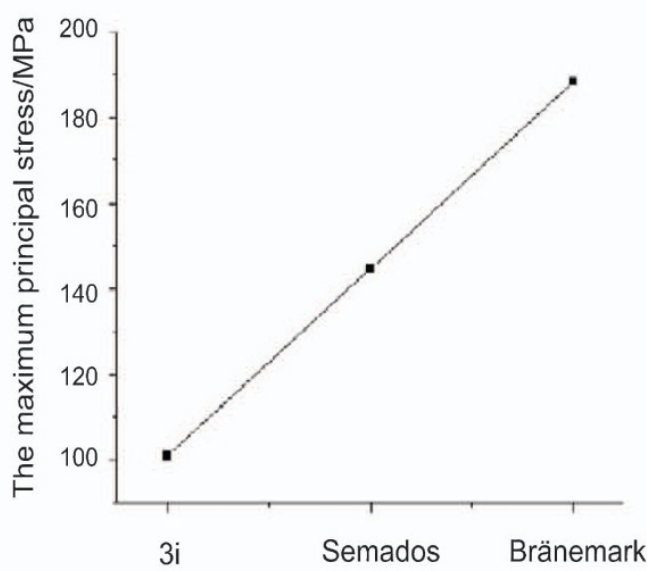

Figure 5 The principal stress distribution and maximum values of three models in the peri-implant bone. The principal stress of distribution is in the peri-implant bone of (a) model I, (b) model II and (c) model III under the same loading condition, respectively. (d) The maximum principal stress values in three models. The maximum value is $100.8 \mathrm{MPa}$ for model I, $144.7 \mathrm{MPa}$ for model II and 188.4 MPa for model III.

external hexagonal connection showed the maximum stress levels, while that in the internal hexagonal connection type showed the minimum (Figure 4).

The principal stresses of all three models were concentrated in the peri-implant cortical bone (Figure $5 \mathrm{a}-5 \mathrm{c}$ ). Model I generate the minimum stress, while model III has the highest. The maximum principal stress value is $100.8 \mathrm{MPa}$ for model I, 144.7 MPa for model II and 188.4 MPa for model III (Figure 5d).

\section{Stiffness analysis}

With ABAQUS, a displacement map of different structures can be used to quantitatively compare the stiffness of all three models (Figure 6a-6c).

In order to clearly distinguish the displacement distribution, we set the deformation scale factor as 20 (which mean the displacement in the figures is amplified by 20 times). There is significant difference in the displacement of the three models, a close observation shows that the maximum is $0.112 \mathrm{~mm}$ for model I, $0.127 \mathrm{~mm}$ for model II and $0.160 \mathrm{~mm}$ for model III. The maximum displacement of the three models is plotted against the model type and shown in Figure 6d.

\section{DISCUSSION}

FEA has been the most common and powerful tool to simulate dental restorations under various loading conditions. ${ }^{12}$ The simulation results can provide much in-depth information not yet available from experiment, and guidelines for innovative designs. Moreover, the precise prediction of dental implant stability and failure mechanisms using FEA is helpful in reducing redundant clinical experiments. Cortical bone loss in particular is one of the leading symptoms of implant failure after osseointegration and the achievement of primary stability. ${ }^{21}$ Bone resorption close to the first thread of osseointegrated implants are frequently observed during initial loading. ${ }^{22}$

The application of any external load to the implant complex must be preceded by the assembly of the abutment onto the implant, achieved by tightening the abutment screw to create a stable screw joint and, thus form the implant complex. It is the first step in preparing the assembled implant complex to transfer loads. So, we simulated a 


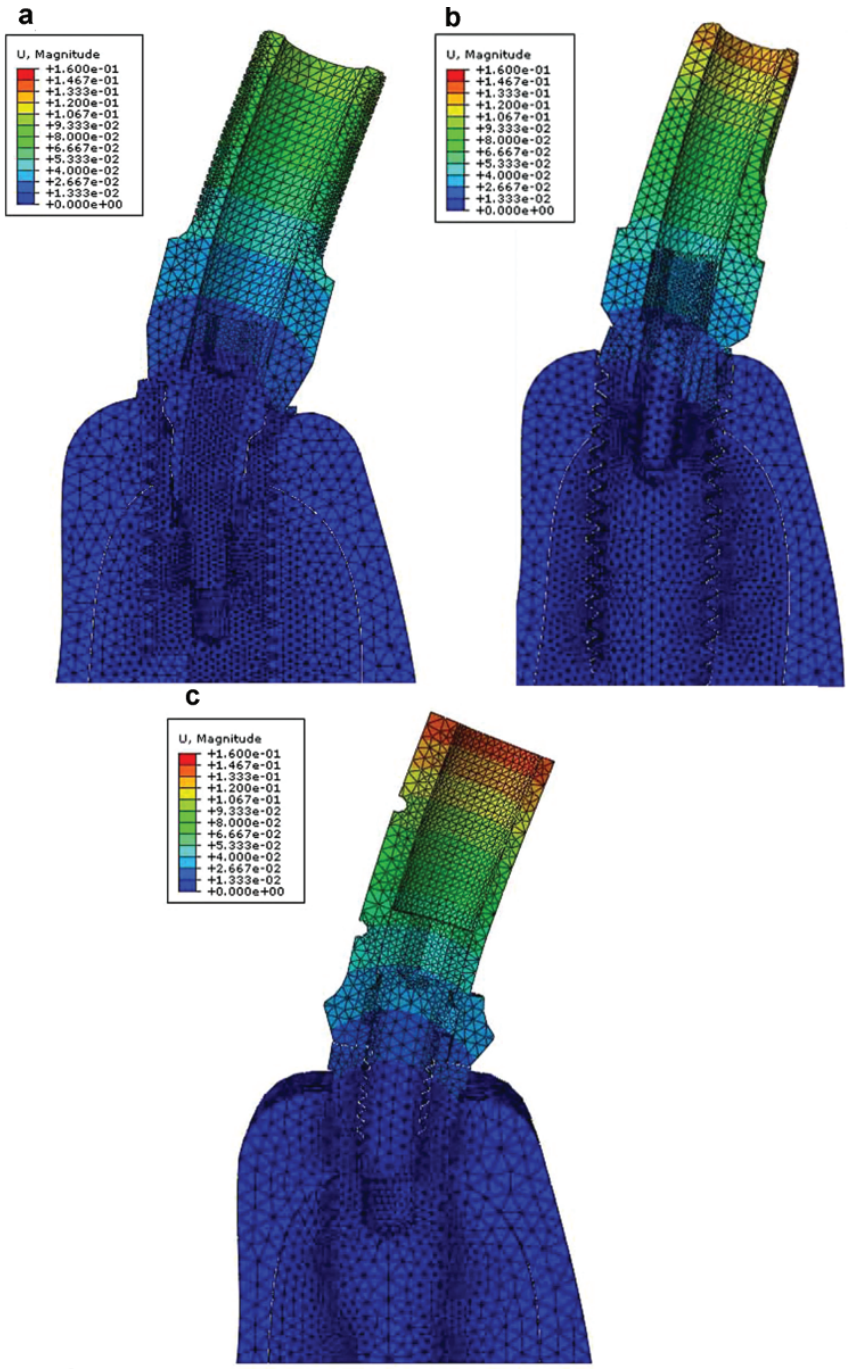

d

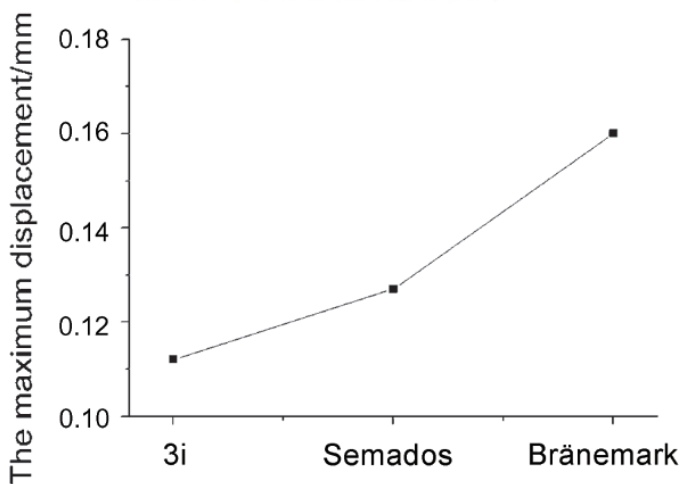

Figure 6 Displacement distribution and maximum displacement of three models. The displacement of distribution is in (a) model I, (b) model II and (c) model III under the same loading condition, respectively. (d) The maximum displacement values in three models. The maximum displacement is $0.112 \mathrm{~mm}$ for model I, $0.127 \mathrm{~mm}$ for model II and $0.160 \mathrm{~mm}$ for model III.

symmetric horizontal rotational torque load of $35 \mathrm{~N} \mathrm{~cm}$ on the abutment screw, which was manufacturers' recommended torques, and tightened in a clockwise direction.

In FEA, the mechanical performance of the implant-abutment interface could be evaluated by von Mises stresses. von Mises stress criterion is important to interpret the stresses within the ductile material, such as the implant material, as deformation occurs when the von Mises stress value exceeds the yield strength. However, principal stresses are used to evaluate the stresses induced around the implants in the bone-a typical brittle material. ${ }^{23}$

As shown in Figure 4, the stresses in model III implant system were generally higher and distributed more uniformly than the stresses in model I and model II. This is attributed to the external and internal hexagonal connection. ${ }^{24-25} \mathrm{We}$ found that the stresses in model II and model III are also concentrated at the collar, and first, second and third thread of the implant. This is in agreement with the previous work by Akca et al. $^{26}$ Compared with the two other implants, model I is obviously different. Figures $4 \mathrm{a}$ and $5 \mathrm{a}$ show that the stresses are concentrated at abutment neck, first thread of implant and the connection section where the abutment inserts deep into the implant; ${ }^{27}$ nevertheless, the stresses near the implant body and the peri-implant cortical bone have notably decreased. The stresses shift from external implant to internal abutment is due to the smaller diameter of the abutment compared to the implant (this design feature is also called platform switching). Some researchers believe that the platform switching configuration had the biomechanical advantage of shifting the stress concentration area away from the cervical bone-implant interface. However, such design increased the stress in the abutment, which leaded to a high tendency of fracture. ${ }^{28}$ We have observed the same phenomenon in our study. But fractures did not occur on the loading above. The principal stress value in the peri-implant cortical bone in model III was the highest, model I had the lowest. Some research reported Brånemark implant had higher marginal bone loss in the first year of function; ${ }^{29}$ however, the simple cumulative survival rate value in first year was $99.2 \% .{ }^{30}$ A comprehensive literature reviews suggest that marginal bone loss is due to the high stress in the periimplant cortical bone.

According to Figure 1, one can see that the connection depth of model I, the section of abutment being inserted into the implant, is the longest among all three implants, but has the lowest maximum von Mises stress value, as demonstrated in Figure 4d. Therefore, the connection depth is a factor affecting the value of von Mises stress. Chu et $a .^{31}$ found that extending the connection depth of abutment and implant could increase the contact area at the abutment-implant interface, and therefore reduces the stress, especially in the oblique loading condition. Steinebrunner et al. ${ }^{32}$ observed that implant systems with long internal tube-in-tube connections showed advantages with regard to longevity and fracture strength compared with systems with shorter internal or external connection designs.

The occlusal forces usually produce non-axial load on the teeth during a normal chewing process, Juodzbalys et al. ${ }^{33}$ found in their investigation that the direction of loading played a major role in determining stress levels, which could vary by up to $85 \%$. Non-axial loading generate stress and displacement much greater than the axial loading. In this study, we simulated a suitable case scenario in a nonaxial loading, in which a $170 \mathrm{~N}$ force was applied onto the top surface of the abutment obliquely at $45^{\circ}$ to the longitudinal axis of the implant, and targeted at the highest stresses occurring within implants for all bone levels tested. The highest stress in model III is $391.5 \mathrm{MPa}$, has not yet exceed the yield strength of titanium (yield point for commercially pure titanium is $462 \mathrm{MPa}$ ). Although this finding indicates that a load of $170 \mathrm{~N}$ applied obliquely at $45^{\circ}$ to the system cannot result in the failure of implant, one can presume that model III with the highest stress is more susceptible to fatigue failure during clinical practice. FEA results also reveal that the deformation and maximal displacement in 
model I are the lowest, while model III has the highest displacement level, as shown in Figure 6. Stiffness refers to the ability of component to resist against elastic deformation under load. Under the same load, the displacement can be used as a reverse indicator of stiffness in mechanics, i.e. the larger displacement, the less stiff structure. From the modeling and simulation, it clearly demonstrates that model I exhibits the smallest maximum displacement indicating the highest stiffness under the same loading conditions as compared with the other two models. Clinical studies have also provided evidence of very high success rates in using $3 \mathrm{i}$ threaded implants. ${ }^{34}$ Yet, we also noticed that there had been far fewer relevant studies with the $3 \mathrm{i}$ system in clinical applications, as compared with the earlier commercial implants, such as Nobel Biocare and Straumann. ${ }^{35}$

Stress distribution in the jaw bone and implant stability in osteoporotic bone are more sensitive to implant designs than those in other normal bones. ${ }^{36}$ Avoiding implant overloading and ensuring a sufficient initial intraosseous stability are the most relevant parameters for promoting a safe biomechanical environment. ${ }^{37}$ Our findings indicate that the stress distribution at implant-abutment connection is predominated by the design characteristics of the interface, which may vary significantly among the manufacturers. And it provides guidance for dentist to predict and avoid the occurrence of clinical complications.

\section{CONCLUSIONS}

Within the limitations of this study, it was concluded that a force of $170 \mathrm{~N}$ applied onto the top surface of the abutment obliquely at $45^{\circ}$ to the longitudinal axis of the implant was unlikely to result in failure in all three implants, and the nonlinear FEA clearly demonstrated that the reduced-diameter $3 \mathrm{i}$ implant system with a hex and a 12-point double internal hexagonal connection is more stable than the other two implant systems. The mechanical characteristics of dental implant systems are closely related to the connection between the implant and abutment. The optimum design of dental implants should be investigated further using the FEA technique and validated with clinical applications.

\section{ACKNOWLEDGMENTS}

\section{This work was supported by Medical Science Foundation of Health}

Department (under contract No. H201034); Six Talent Summit Foundation of Jiangsu Province, China (under contract No. 2010-WS081) and a Project Funded by the Priority Academic Program Development of Jiangsu Higher Education Institutions. The authors thank Dr. Mingdong Cai of Schlumberger, USA for valuable discussions and criticisms on the manuscript.

1 Jemt T. Single implants in the anterior maxilla after 15 years of follow-up: comparison with central implants in the edentulous maxilla. Int J Prosthodont 2008; 21(5): 400408.

2 Moeintaghavi A, Radvar M, Arab H et al. Evaluation of 3- to 8-year treatment outcomes and success rates with six implant brands in partially edentulous patients. J Oral Implantol; e-pub ahead of print 2 December 2010; doi:http://dx.doi.org/10.1563/ AAID-JOI-D-10-00117

3 Simonis $\mathrm{P}$, Dufour $\mathrm{T}$, Tenenbaum $\mathrm{H}$. Long-term implant survival and success: a 10 16-year follow-up of non-submerged dental implants. Clin Oral Implants Res 2010; 21(7): 772-777.

4 Albrektsson T, Brånemark PI, Hansson HA et al. Osseointegrated titanium implants. Requirements for ensuring a long-lasting, direct bone-to-implant anchorage in man. Acta Orthop Scand 1981; 52(2): 155-170.

5 Kitagawa T, Tanimoto Y, Odaki M et al. Influence of implant/abutment joint designs on abutment screw loosening in a dental implant system. J Biomed Mater Res B Appl Biomater 2005; 75(2): 457-463.

6 Theoharidou A, Petridis HP, Tzannas K et al. Abutment screw loosening in singleimplant restorations: a systematic review. Int J Oral Maxillofac Implants 2008; 23(4): 681-690.
7 Geng JP, Tan KB, Liu GR. Application of finite element analysis in implant dentistry: a review of the literature. J Prosthet Dent 2001; 85(6): 585-598.

8 Binon PP. Implants and components: entering the new millennium. Int J Oral Maxillofac Implants 2000; 15(1): 76-94.

9 Balik A, Ozdemir Karatas M, Keskin H. Effects of different abutment connection designs on the force distribution around commercially available dental implants: a 3d finite element analysis. J Oral Implantol; e-pub ahead of print 16 May 2011; doi:http://dx.doi.org/10.1563/AAID-JOI-D-10-00127

10 Bernardes SR, de Araujo CA, Neto AJ et al. Photoelastic analysis of stress patterns from different implant-abutment interfaces. Int J Oral Maxillofac Implants 2009; 24(5): 781-789.

11 Rodriguez-Ciurana $X$, Vela-Nebot $X$, Segala-Torres $M$ et al. Biomechanical repercussions of bone resorption related to biologic width: a finite element analysis of three implant-abutment configurations. Int J Periodontics Restorative Dent 2009; 29(5): 479-487.

12 Wakabayashi N, Ona M, Suzuki T et al. Nonlinear finite element analyses: advances and challenges in dental applications. J Dent 2008; 36(7): 463-471.

13 Burak Ozcelik T, Ersoy E, Yilmaz B. Biomechanical evaluation of tooth- and implantsupported fixed dental prostheses with various nonrigid connector positions: a finite element analysis. J Prosthodont 2011; 20(1): 16-28.

14 Kong L, Gu Z, LiT et al. Biomechanical optimization of implant diameter and length for immediate loading: a nonlinear finite element analysis. Int J Prosthodont 2009; 22(6): 607-615.

15 Akca K, Iplikcioglu H. Finite element stress analysis of the influence of staggered versus straight placement of dental implants. Int J Oral Maxillofac Implants 2001; 16(5): 722-730.

16 Pierrisnard L, Hure G, Barquins $M$ et al. Two dental implants designed for immediate loading: a finite element analysis. Int J Oral Maxillofac Implants 2002; 17(3): 353362.

17 Alkan I, Sertgoz A, Ekici B. Influence of occlusal forces on stress distribution in preloaded dental implant screws. J Prosthet Dent 2004; 91(4): 319-325.

18 Yu HY, Cai CZ, Zhou ZR et al. Fretting behavior of cortical bone against titanium and its alloy. Wear 2005; 259(7/8/9/10/11/12): 910-918.

19 Grant JA, Bishop NE, Götzen N et al. Artificial composite bone as a model of human trabecular bone: the implant-bone interface. J Biomech 2007; 40(5): 1158-1164.

20 Kawaguchi T, Kawata T, Kuriyagawa T et al. In vivo 3-dimensional measurement of the force exerted on a tooth during clenching. J Biomech 2007; 40(2): 244-251.

21 Albrektsson T, Zarb G, Worthington $\mathrm{P}$ et al. The long-term efficacy of currently used dental implants: a review and proposed criteria of success. Int J Oral Maxillofac Implants 1986; 1(1): 11-25.

22 Berglundh T, Lindhe J. Dimension of the periimplant mucosa. Biological width revisited. J Clin Periodontol 1996; 23(10): 971-973.

23 Tabata LF, Assuncao WG, Adelino Ricardo Barao V et al. Implant platform switching: biomechanical approach using two-dimensional finite element analysis. J Craniofac Surg 2010; 21(1): 182-187.

24 Chun HJ, Shin HS, Han $\mathrm{CH}$ et al. Influence of implant abutment type on stress distribution in bone under various loading conditions using finite element analysis. Int J Oral Maxillofac Implants 2006; 21(2): 195-202.

25 Maeda $\mathrm{Y}$, Satoh T, Sogo M. In vitro differences of stress concentrations for internal and external hex implant-abutment connections: a short communication. J Oral Rehabil 2006; 33(1): 75-78.

26 Akca K, Cehreli MC, Iplikcioglu H. Evaluation of the mechanical characteristics of the implant-abutment complex of a reduced-diameter morse-taper implant. A nonlinear finite element stress analysis. Clin Oral Implants Res 2003; 14(4): 444-454.

27 Segundo RM, Oshima HM, Silva IN et al. Stress distribution on external hexagon implant system using 3d finite element analysis. Acta Odontol Latinoam 2007; 20(2): 79-81.

28 Maeda Y, Miura J, Taki I et al. Biomechanical analysis on platform switching: is there any biomechanical rationale? Clin Oral Implants Res 2007; 18(5): 581-584.

29 Bilhan $\mathrm{H}$, Kutay $\mathrm{O}$, Arat $\mathrm{S}$ et al. Astra Tech, Brånemark, and ITI implants in the rehabilitation of partial edentulism: two-year results. Implant Dent 2010; 19(5): 437-446.

30 Ostman PO, Wennerberg A, Albrektsson T. Immediate occlusal loading of NanoTite PREVAIL implants: a prospective 1-year clinical and radiographic study. Clin Implant Dent Relat Res 2010; 12 (1): 39-47.

31 Chu CM, Huang HL, Hsu JT et al. Influences of internal tapered abutment designs on bone stresses around a dental implant: three-dimensional finite element method with statistical evaluation. J Periodontol 2011; 83(1): 111-118.

32 Steinebrunner L, Wolfart S, Ludwig K et al. Implant-abutment interface design affects fatigue and fracture strength of implants. Clin Oral Implants Res 2008; 19(12): 1276-1284.

33 Juodzbalys G, Kubilius R, Eidukynas et al. Stress distribution in bone: single-unit implant prostheses veneered with porcelain or a new composite material. Implant Dent 2005; 14(2): 166-175.

34 Davarpanah M, Martinez H, Etienne D et al. A prospective multicenter evaluation of 1,583 3i implants: 1- to 5-year data. Int J Oral Maxillofac Implants 2002; 17(6): 820-828.

35 Bhatavadekar N. Helping the clinician make evidence-based implant selections. A systematic review and qualitative analysis of dental implant studies over a 20 year period. Int Dent J 2010; 60(5): 359-369.

36 Xiao JR, Li YF, Guan SM et al. The biomechanical analysis of simulating implants in function under osteoporotic jawbone by comparing cylindrical, apical tapered, neck 
tapered, and expandable type implants: a 3-dimensional finite element analysis. $J$ Oral Maxillofac Surg 2011; 69(7): 273-281.

37 Pessoa RS, Muraru L, Junior EM et al. Influence of implant connection type on the biomechanical environment of immediately placed implants-CT-based nonlinear, three-dimensional finite element analysis. Clin Implant Dent Relat Res 2009; 12(3): 219-234.

cc This work is licensed under a Creative Commons SOMERIGHISHESERVED Attribution-NonCommercial-NoDerivative Works 3.0 Unported License. To view a copy of this license, visit http:// creativecommons.org/licenses/by-nc-nd/3.0 